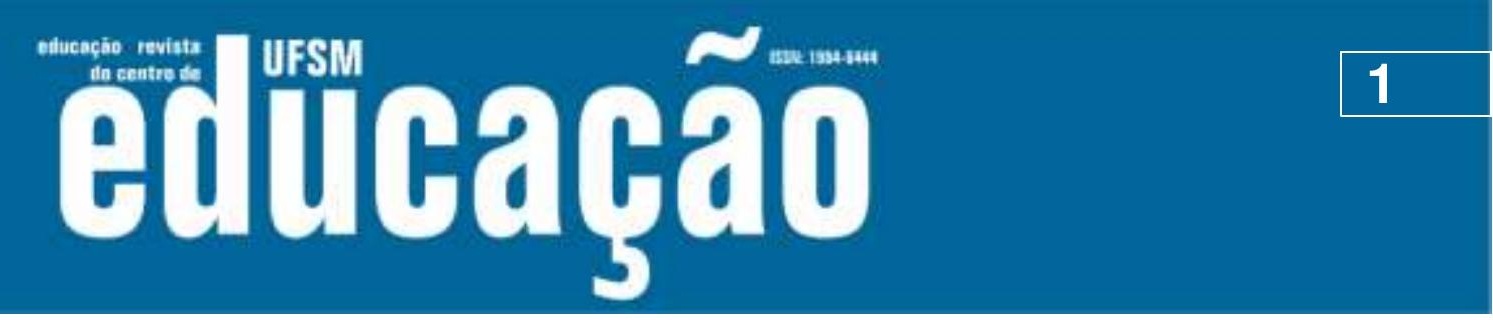

ISSN: 1984-6444 | http://dx.doi.org/10.5902/1984644432179

\title{
Impactos financeiros de uma política de redução do número de alunos por turma: o caso Português
}

\author{
Financial impacts of a policy of class-size reduction: the Portuguese \\ case
}

\author{
Pedro Ribeiro Mucharreira \\ Instituto de Educação, Universidade de Lisboa \\ ISCE - Instituto Superior de Ciências Educativas \\ Belmiro Gil Cabrito \\ Instituto de Educação, Universidade de Lisboa \\ Luís Capucha \\ Instituto Universitário de Lisboa (ISCTE-IUL)
}

\section{RESUMO}

O presente artigo resulta da participação dos autores num projeto de investigação, financiado pelo Ministério da Educação português, que suportou um novo enquadramento legal relativo à dimensão das turmas. A presente investigação pretende promover a reflexão em torno dos benefícios decorrentes da diminuição do número de alunos por turma procurando, neste sentido, demonstrar que as despesas daqui resultantes são habitualmente sobrevalorizadas ao serem determinadas em função dos custos brutos de um trabalhador para o Estado e não tendo em conta os custos líquidos correspondentes. Para este exercício académico levou-se em linha de conta o caso português e os custos de um professor para o sistema público de ensino em Portugal, a preços de referência de 2017/2018. Adicionalmente a estes custos líquidos torna-se necessário considerar outros fatores que justificam estas políticas, como os efeitos pedagógicos positivos nas aprendizagens dos alunos, bem como poupanças resultantes de uma menor percentagem de insucesso e abandono escolares. Com este trabalho pretende-se contribuir para uma melhor reflexão sobre esta temática, sensibilizando diferentes atores educativos para uma aproximação mais fina à relação entre custos e benefícios diretos e indiretos que podem resultar de uma política de redução do número de alunos por turma.

Palavras-chave: Redução do número de alunos por turma; Política educativa; Economia da educação.

\section{ABSTRACT}

This research emerges in the follow up of a research project, funded by the Portuguese Ministry of Education, and which supported a new legal regulation regarding the size 


\section{DEM

ISSN: 1984-6444 | http://dx.doi.org/10.5902/1984644432179

número de equipamentos, professores, técnicos de educação, funcionários da administração, etc.

No entanto, afastar desde logo aquela medida em função dos encargos financeiros que pode vir a acarretar seria negligenciar um conjunto de efeitos positivos no curto, médio e longo prazo. No curto prazo, é esquecer os efeitos pedagógicos possíveis com resultados no sucesso escolar diminuindo, assim, os encargos com as repetências e, por outro lado, no médio e longo prazo, é negligenciar o efeito spill over de uma população mais educada e, finalmente (ainda que muitos outros efeitos positivos possam ser identificados) é assumir que mais um professor ou mais um funcionário constituirá uma despesa acrescida para o Estado ao invés de ser perspetivado como um investimento. Para além disso, essa despesa é, comumente, sobrevalorizada, tal como pretendemos de seguida demonstrar.

No presente trabalho pretendemos, exatamente, em primeiro lugar, e partindo da literatura, alertar para alguns dos benefícios decorrentes da diminuição do número de alunos por turma e, em segundo lugar, demonstrar que as despesas resultantes são habitualmente sobrevalorizadas, ao serem determinadas em função dos custos brutos de um trabalhador para o Estado e não dos custos líquidos correspondentes. Para além desta reflexão em torno dos custos líquidos dos novos docentes a contratar, procuramos igualmente demonstrar as poupanças que poderiam resultar para o Estado português da diminuição das retenções dos alunos.

Neste exercício académico iremos levar em conta o caso português e os custos de um professor para o sistema público de ensino em Portugal, a preços de 2017/2018. Para além disso, enquadramos as poupanças para o Estado português resultantes da diminuição da retenção de alunos entre o $1^{\circ}$ ciclo e o $3^{\circ}$ ciclo do ensino básico (ensino fundamental), bem como as que resultariam da cessação dos programas de combate ao insucesso e abandono escolares, com os seus respetivos custos associados.

\section{Enquadramento Teórico}

A problemática em torno da dimensão das turmas, quer na ótica dos custos, quer na ótica do trabalho pedagógico e dos resultados escolares, tem sido objeto de 


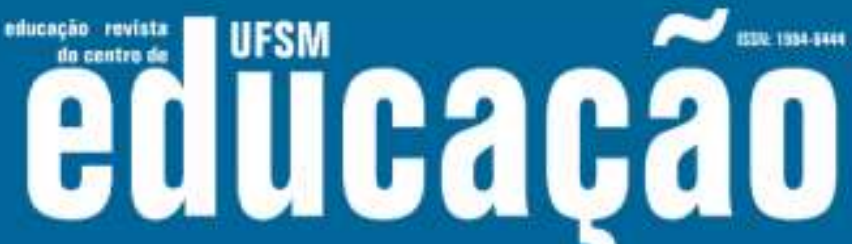

ISSN: 1984-6444 | http://dx.doi.org/10.5902/1984644432179

um grande número de estudos, com conclusões por vezes significativamente divergentes. Apesar destes antagonismos, também é de salientar que os principais estudos de referência, a nível internacional, apontam para a conclusão de que turmas mais pequenas tendem a produzir resultados pedagógicos positivos, principalmente entre os alunos oriundos de meios socioeconomicamente mais desfavorecidos (KRUEGER, 2003; SERVE, 2005). Ao nível do contexto português é de salientar a presença destas mesmas evidências, num estudo recente financiado pelo Ministério da Educação (CAPUCHA; CABRITO; CARVALHO; SEBASTIÃO; MARTINS; CAPUCHA; ROLDÃO; TAVARES; MUCHARREIRA, 2017).

Os resultados deste projeto de investigação suportaram a publicação de um novo normativo legal que introduziu uma redução do número de alunos por turma no início de cada ciclo de ensino, sendo expectável a implementação gradual da medida nos restantes anos (PORTUGAL, 2018). O Quadro 1 apresenta a evolução recente até ao presente ano letivo.

Quadro 1 - Legislação relativa à dimensão de turmas em Portugal, 2001 a 2018/2019, por nível de ensino

\begin{tabular}{|c|c|c|c|c|}
\hline $\begin{array}{l}\text { CICLOS DE } \\
\text { ENSINO }\end{array}$ & $\begin{array}{l}\text { LEGISLAÇÃO } \\
(2001-2004)\end{array}$ & $\begin{array}{l}\text { LEGISLAÇÃO } \\
\text { (2004-2013) }\end{array}$ & $\begin{array}{c}\text { LEGISLAÇÃ } \\
\text { O (2013- } \\
2017)\end{array}$ & $\begin{array}{l}\text { LEGISLAÇÃO } \\
(2018 / 2019)\end{array}$ \\
\hline $\begin{array}{l}\text { 10 ciclo do } \\
\text { Ensino Básico }\end{array}$ & $\begin{array}{l}25 \text { (não pode } \\
\text { ultrapassar) }\end{array}$ & $\begin{array}{l}24 \text { (não pode } \\
\text { ultrapassar) }\end{array}$ & 26 alunos & 24-26 alunos \\
\hline $\begin{array}{l}2^{\circ} \text { ciclo do } \\
\text { Ensino Básico }\end{array}$ & 25-28 alunos & 24-28 alunos & 26-30 alunos & $\begin{array}{l}24-28 \text { alunos ( } 5^{\circ} \text { ano) } \\
26-30 \text { alunos ( } 6^{\circ} \text { ano) }\end{array}$ \\
\hline $\begin{array}{l}3^{\circ} \text { ciclo do } \\
\text { Ensino Básico }\end{array}$ & 25-28 alunos & 24-28 alunos & 26-30 alunos & $\begin{array}{l}\left.24-28 \text { alunos ( } 7^{\circ} \text { ano }\right) \\
26-30 \text { alunos ( } 8^{\circ} \text { e } 9^{\circ} \text { ano) }\end{array}$ \\
\hline $\begin{array}{l}\text { Ensino } \\
\text { Secundário } \\
\text { /Regular }\end{array}$ & 25-28 alunos & 24-28 alunos & $26-30$ alunos & 26-30 alunos \\
\hline $\begin{array}{l}\text { Ensino } \\
\text { Secundário } \\
\text { /Cursos } \\
\text { Profissionais }\end{array}$ & - & $\begin{array}{l}18-23 \text { (min. de } 15 \\
\text { e máx. } 28, \text { quando } \\
\text { justificado) }\end{array}$ & 24-30 alunos & 24-30 alunos \\
\hline
\end{tabular}

Fonte: Adaptado de Capucha, Cabrito, Carvalho, Sebastião, Martins, Capucha, Roldão, Tavares e Mucharreira (2017).

Para além de uma melhoria nas aprendizagens dos alunos, inseridos em turmas de menor dimensão, diversos estudos salientam, de igual forma, efeitos 


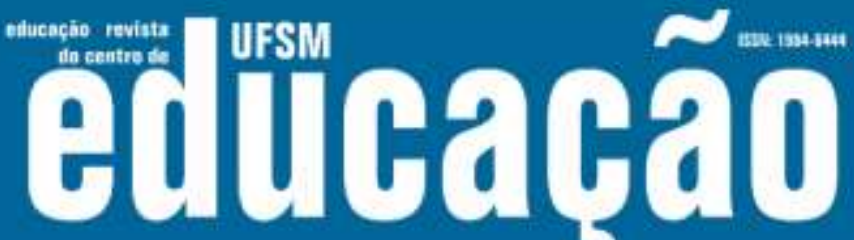

ISSN: 1984-6444 | http://dx.doi.org/10.5902/1984644432179

positivos ao nível do ambiente escolar e do trabalho docente (FINN; ACHILLES, 1999; KRUEGER, 2003; JEPSEN; RIVKIN, 2009; HARFITT, 2015; BLATCHFORD; CHAN; GALTON; LAI; LEE, 2016). Outros dois aspetos que parecem ser consensuais, quando se investiga uma política de redução do número de alunos por turma, é que esta não deve ser perspetivada de forma isolada, mas sim em conjugação com todo um conjunto de outras políticas educativas, e o facto de que a sua materialização implicará, necessariamente, um acréscimo dos custos financeiros, mormente justificados pela necessidade de contratação de mais docentes e construção ou reabilitação de novas salas.

Apesar disto, diversos autores referem a forma como estes custos associados podem ser atenuados, a médio e longo prazo, ao levar em linha de conta uma redução da retenção e do abandono escolares, o aumento da escolaridade da população e o consequente aumento da produtividade das economias, do poder de compra, do reforço da equidade e justiça sociais, entre outros aspetos que, genericamente, podem fomentar o crescimento e desenvolvimento económico.

Neste âmbito, importa enquadrar estes benefícios indiretos com a Teoria do Capital Humano (SCHULTZ, 1961; BECKER, 1964) e de inúmeras investigações que demonstram essa relação positiva - um efeito spill over - entre níveis académicos e a elevação dos níveis de crescimento e desenvolvimento económico (PSACHAROPOULOS, 1994; PSACHAROPOULOS; PATRINOS, 2004).

Apesar destas externalidades positivas poderem ocorrer no médio e longo prazo, a decisão de reduzir o número de alunos por turma é uma medida com impactos financeiros imediatos, decorrentes da necessidade em contratar novos professores, mais assistentes técnicos e operacionais, bem como em construir, reorganizar ou reequipar as salas de aula.

Percebe-se assim a dificuldade, do ponto de vista financeiro, em proceder a reduções significativas na constituição das turmas, tendo em conta o rigor e constrangimentos orçamentais das escolas e a prioridade a dar, muitas vezes, à implementação de políticas educativas alternativas (KRUEGER, 2003; SERVE, 2005). 


\section{IN Hem

ISSN: 1984-6444 | http://dx.doi.org/10.5902/1984644432179

Nesse sentido, o legislador depara-se com dificuldades e oportunidades perante uma política como a de redução do número de alunos por turma. Esta dicotomia é bem expressa no modelo abaixo.

Quadro 2 - Modelo de impactos de uma medida de redução das turmas

\begin{tabular}{l|l}
\multicolumn{1}{c}{+ Alunos } & - Dependentes dos contextos culturais. \\
- Menores custos com salários docentes e & - Dependentes da formação dos docentes, \\
salas de aula. & organização curricular e estratégias \\
- Custos de longo prazo com saúde e & pedagógicas. \\
criminalidade. & - Professores mais experientes mas \\
- Trabalhadores menos produtivos. & potencialmente mais descontentes. \\
& - Indisciplina e pior comportamento em sala \\
de aula. \\
\hline Impactos Financeiros & \multicolumn{1}{c}{ Impactos Pedagógicos } \\
\hline - Maior despesa no plano imediato. & - Melhor relação docente/aluno. \\
- Retorno mais significativo com aumento & - Oportunidade para implementar \\
da escolaridade e redução do insucesso & escolar. \\
escolar no médio e longo prazo. & - Impactos pedagógicos e resultados \\
& escolares positivos, particularmente entre \\
& os alunos de condição social \\
& desfavorecida. \\
& - Mais professores, alguns menos \\
& experientes. \\
& - Alunos
\end{tabular}

Fonte: Adaptado de Capucha, Cabrito, Carvalho, Sebastião, Martins, Capucha, Roldão, Tavares e Mucharreira (2017).

Não se esgotando os encargos financeiros de uma política de redução do número de alunos por turma na contratação de docentes, Whitehurst e Chingos (2011) estimam que, nos EUA, a redução de 1 aluno no rácio aluno/professor representaria uma necessidade imediata na ordem de 225 mil novas salas no país. Alertam, igualmente, que a questão não deve estar apenas centrada em se procurar perceber se uma política de redução do número de alunos por turma tem efeitos positivos, mas, 


\section{L

ISSN: 1984-6444 | http://dx.doi.org/10.5902/1984644432179

essencialmente, procurar compreender se esta política é a mais rentável e adequada em comparação com outras (HANUSHEK, 1997; NORMORE; ILON, 2006). Neste sentido, e em termos económico-financeiros, a que permita a melhor aplicação dos recursos financeiros e orçamentais tendo em vista o sucesso educativo e, em última instância, suportando o crescimento e desenvolvimento económico (MUCHARREIRA; ANTUNES, 2015).

Por outras palavras, o que Whitehurst e Chingos (2011) indagavam era se a aplicação de 1 unidade monetária em políticas de redução do número de alunos por turma pode implicar um retorno maior que 1 unidade monetária em aplicações alternativas, como um maior investimento no ensino pré-escolar e na revisão do currículo ou investimento em novas tecnologias, um aumento do vencimento dos professores ou um maior investimento na formação de professores. Não apenas na formação inicial, tendo em conta as especificidades de cada grupo de recrutamento docente (MUCHARREIRA; CABRITO; CERDEIRA, 2018), como ao nível da formação contínua, particularmente a que possa ser contextualizada à realidade de cada escola e/ou agrupamento de escolas e aos seus projetos educativos (MUCHARREIRA, 2016; MUCHARREIRA, 2017; MUCHARREIRA, 2018). De facto, os decisores devem ter sempre em conta o custo de oportunidade das suas decisões, procurando avaliar qual será mais eficiente do ponto de vista económico-financeiro, num determinado momento (MITCHELL; MITCHELL, 2003) e, simultaneamente, aferir quanto aos maiores benefícios que possa trazer do ponto de vista social (CABRITO, 2002).

Paralelamente a estas reflexões, surge, desta forma, o debate acerca dos custos inerentes à não implementação deste tipo de políticas que possam promover uma dimensão adequada das turmas. Tais reflexões afiguram-se como estratégicas pois, conforme exposto anteriormente, apesar da implementação destas políticas poder implicar um acréscimo significativo de custos, será de ter em conta outros impactos económicos e sociais a médio e longo prazo - eventualmente de maior dimensão - decorrentes da decisão de não se reduzir o número de alunos por turma. Entre estes impactos podem elencar-se, por exemplo, uma menor taxa de graduação no ensino superior, decréscimo da produtividade, vencimentos médios inferiores, 


\section{LFM

ISSN: 1984-6444 | http://dx.doi.org/10.5902/1984644432179

impactos negativos na participação cívica, nos índices de felicidade, o que no conjunto se traduzirá em menor retorno fiscal para o Estado.

Do exposto já se pode perceber que a redução do tamanho das turmas pode ser, mais que uma decisão educativa, uma decisão política (KRUEGER, 1999), dependente dos objetivos educativos que a governação persegue. Efetivamente, e apesar da falta de consensualidade, assumindo que aquela redução terá ganhos ao nível pedagógico - concretizados em indicadores como maiores taxas de sucesso, menor número de retenções, aprendizagens mais significativas, melhores empregos futuros, entre outros -, seria de esperar que os decisores reequacionassem as suas prioridades ao nível da administração educacional.

\section{Metodologia}

No que diz respeito à metodologia, a investigação encontra-se estruturada numa abordagem estatística e descritiva (BOGDAN; BIKLEN, 1994; BARDIN, 2009) do fenómeno dos impactos financeiros decorrentes de uma política de redução do número de alunos por turma.

Para este exercício académico, considerou-se o caso português e os custos de um professor para o sistema de ensino público em Portugal, tendo em mente uma abordagem metodológica destinada a estimar não apenas os custos brutos, mas, da mesma forma, os custos líquidos de contratação de um professor a preços de referência de 2017/2018 e, posteriormente, cruzar esse custo com as projeções das turmas a criar no sistema educativo português, no ano letivo de 2017/2018.

Tendo em conta estes valores estimados, decorrentes de uma política de redução do número de alunos por turma, procurou-se também calcular os valores que se podem constituir como poupanças para o orçamento do Estado português. Para as estimativas apresentadas, utilizou-se a recolha e análise documental a partir de diferentes bases de dados, nomeadamente as fornecidas pelo Ministério da Educação no decurso do projeto de investigação atrás mencionado.

Para estes cálculos foi necessário partir-se de pressupostos cuja razoabilidade fosse inteligível, em função dos quais se determinaram aqueles custos. 


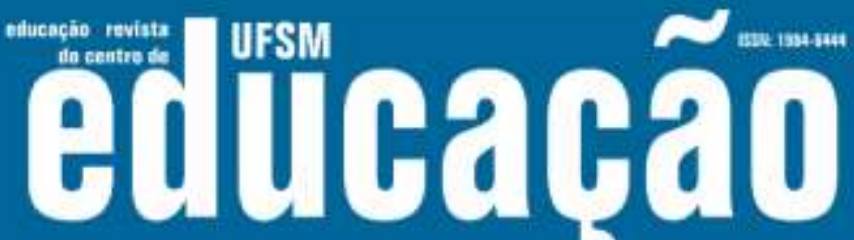

ISSN: 1984-6444 | http://dx.doi.org/10.5902/1984644432179

1 - Para cada novo docente teve-se em consideração o vencimento correspondente ao Índice 167, com base na presunção de que qualquer novo professor será contratado no início da carreira.

2 - Tomaram-se em conta todos os encargos que cada docente acarreta para o Estado e que correspondem às despesas diretas do Estado com esse professor.

3 - Tomaram-se em conta todos os retornos diretos e indiretos que o Estado virá a receber a partir do rendimento que distribuiu por cada profissional, assumindose, aqui, o Estado como um conjunto de organismos que ultrapassa o simples sistema governativo, abrangendo diversos sistemas geridos pelo Estado e que garantem o bem-estar das populações e/ou o desempenho, pelo Estado, das suas funções sociais. Considerou-se, assim, que cada docente representa, simultaneamente, uma despesa e uma fonte de receita para o Estado. A despesa é o vencimento nominal correspondente a cada índice salarial. A fonte de receitas corresponde à parte do vencimento de que o Estado irá apropriar-se indiretamente através de impostos e contribuições.

Tendo presente os pressupostos atrás enunciados, assumem-se neste estudo duas tipologias de estudo. Os Custos Brutos, isto é, o custo real de um funcionário para o Ministério da Educação (ME), e que resulta da adição ao vencimento nominal do funcionário dos $23,75 \%$ desse vencimento, que o ME entrega à Segurança Social, e ainda do subsídio de refeição. Por outro lado, os Custos Líquidos obtiveram-se assumindo que o funcionário não é, apenas, uma fonte de despesa, mas também uma fonte de receita, decorrente dos retornos diretos e indiretos sobre o respetivo vencimento.

Foi igualmente necessário recorrer a estatísticas oficiais, mormente as disponibilizadas no Pordata (2019). Neste sentido, e para auxiliar a metodologia de cálculo dos benefícios financeiros públicos indiretos, tornou-se importante consultar o peso do valor arrecadado em sede de IVA (imposto sobre o valor acrescentado imposto indireto sobre o consumo) pelo Estado em 2018 em função do total das despesas de consumo dos particulares. 


\section{Husm outuarao}

ISSN: 1984-6444 | http://dx.doi.org/10.5902/1984644432179

Considerou-se esse valor obtido como a taxa média de IVA paga pelas famílias no período, o qual corresponde a cerca de $12,6 \%$. Observem-se os valores abaixo obtidos no Pordata (2019) para 2017/2018:

Rendimento Disponível Bruto dos Particulares: 132.602,8 (milhões de euros)

Taxa de poupança dos particulares - 4,5\%

Despesas de consumo dos particulares - 126.635,67 (milhões de euros)

IVA - 16.001,4 (milhões de euros)

IVA/Despesas de consumo (taxa média) - 12,6\%.

Quer dizer que $12,6 \%$ das despesas realizadas pelos consumidores finais são entregues ao Estado sob a forma do IVA.

Não tivemos em consideração outros impostos indiretos mais específicos e determinaram-se, desta forma, os "benefícios indiretos" que o Estado recebe da parte dos seus funcionários, quando gastam a parte não poupada do seu rendimento disponível.

\section{Resultados}

Tendo em conta o enquadramento teórico e metodológico, são apresentados de seguida os custos brutos e líquidos de uma nova contratação docente no sistema educativo português a preços de 2017/2018, para além das possíveis poupanças resultantes da diminuição da retenção de alunos entre o $1^{\circ}$ ciclo e $03^{\circ}$ ciclo do ensino básico (ensino fundamental), bem como as que resultariam da cessação dos programas de promoção do sucesso escolar.

Tendo em atenção o projeto de investigação em que os autores participaram (CAPUCHA; CABRITO; CARVALHO; SEBASTIÃO; MARTINS; CAPUCHA; ROLDÃO; TAVARES; MUCHARREIRA, 2017), estimou-se que, se a redução do número de alunos por turma materializada neste ano letivo tivesse ocorrido em $2017 / 2018$, isso implicaria a criação de cerca de 1036 novas turmas e cerca de 1057 novos horários docentes (equivalentes a tempo integral), professores que seriam contratados no 


\section{THEm

ISSN: 1984-6444 | http://dx.doi.org/10.5902/1984644432179

Índice 167, equivalente ao início da carreira (recorde-se que a alteração legal deu-se apenas em 2018/2019). Observe-se o Quadro 3:

Quadro 3 - Número de Turmas e Horários Docentes a Criar, em 2017/2018

\begin{tabular}{|c|c|c|}
\hline ANOS DE INÍCIO DE CICLO & TURMAS A CRIAR & $\begin{array}{c}\text { HORÁRIOS } \\
\text { DOCENTES A CRIAR } \\
\text { (ETI) }\end{array}$ \\
\hline $1^{\circ}$ ano & 209 & 217 \\
\hline $5^{\circ}$ ano & 174 & 178 \\
\hline $7^{\circ}$ ano & 208 & 236 \\
\hline $10^{\circ}$ ano $-\mathrm{CCH}$ & 184 & 190 \\
\hline $1^{\circ}$ ano $-\mathrm{CP}$ & 261 & 236 \\
\hline Totais & $\mathbf{1 0 3 6}$ & $\mathbf{1 0 5 7}$ \\
\hline
\end{tabular}

Fonte: Capucha, Cabrito, Carvalho, Sebastião, Martins, Capucha, Roldão, Tavares e Mucharreira (2017).

As estimativas acima apresentadas são valores agregados que poderão sofrer algumas modificações em função de diversos fatores, como por exemplo, uma ação política que operasse uma distribuição dos alunos entre as turmas sobredimensionadas e subdimensionadas ou a implementação de dinâmicas de mobilidade de professores que permitisse que professores sem turmas atribuídas fossem lecionar noutras escolas onde a redução do número de alunos por turma viesse a exigir novas contratações ${ }^{1}$.

Desta forma, apresentam-se os cálculos que permitem chegar a valores de referência que poderão perspetivar de forma mais objetiva os reais impactos financeiros que uma política de redução do número de alunos por turma pode implicar no sistema educativo português. O Quadro 4 mostra os cálculos efetuados para um professor no início de carreira.

\footnotetext{
${ }^{1}$ Relembre-se que não entram aqui considerações sobre o impacto da acentuada quebra nas taxas de natalidade, o qual introduz uma dinâmica suficiente para alterar significativamente estes números.
} 
ISSN: 1984-6444 | http://dx.doi.org/10.5902/1984644432179

Quadro 4 - Encargos Financeiros Anuais do Estado / Custo Padrão Docente do Índice 167 em 2017/2018 (em euros)

\begin{tabular}{|c|c|}
\hline Encargos Financeiros Públicos & \\
\hline Vencimento base (Índice 167) (1) & $1.518,63$ \\
\hline Segurança Social /CGA (23,75\%) (2) & 360,67 \\
\hline Total despesa mensal do Estado (1)+(2) & $1.879,30$ \\
\hline Total anual (14 meses) (3) & $26.310,26$ \\
\hline Subsídio de refeição (11 meses) (4) & $1.014,4$ \\
\hline $\begin{array}{l}\text { Encargo Total Anual com um novo professor, contratado com o Índice } \\
167(A)=(3)+(4)\end{array}$ & 27.324,66 \\
\hline Benefícios Financeiros Públicos Diretos & \\
\hline Encargo total anual (Índice 167) & $27.324,66$ \\
\hline Vencimento base (14 meses) & $21.260,82$ \\
\hline Retenção na fonte IRS (15,3\%) (1) & $3.252,91$ \\
\hline Segurança Social / CGA (11\%) (2) & $2.338,69$ \\
\hline ADSE (3,5\%) (3) & 744,13 \\
\hline Total Benefícios Financeiros Públicos Diretos $(B)=(1)+(2)+(3)$ & $6.335,73$ \\
\hline Benefícios Financeiros Públicos Indiretos / Benefícios Económicos & \\
\hline Vencimento líquido (Índice 167) (1) & $14.925,09$ \\
\hline Subsídio de refeição (11 meses) (2) & $1.014,4$ \\
\hline Rendimentos do fator trabalho (RDP) (3) $=(1)+(2)$ & $15.939,49$ \\
\hline $\begin{array}{l}\text { Consumo previsto (95,5\% taxa consumo, em função RDP- } 2^{\circ} \text { trimestre } \\
\text { 2018) }\end{array}$ & $15.222,21$ \\
\hline $\begin{array}{l}\text { IVA potencial a arrecadar (12,6\% de taxa média de IVA - IVA/Consumo } \\
\text { previsto) (4) }\end{array}$ & $1.918,00$ \\
\hline $\begin{array}{l}\text { Total Benefícios Financeiros Públicos Indiretos / Benefícios } \\
\text { Económicos }(C)=(4)\end{array}$ & 1918,00 \\
\hline
\end{tabular}

Vencimento Líquido Anual Docente Índice 167= (A) - ((B) + (C)) (Vencimento Bruto Anual Docente Índice 167 - Total Benefícios Públicos Diretos - Total Benefícios Públicos Indiretos)

19.070,93 euros / docente (Índice 167)

Fonte: Elaboração própria - Dados obtidos no Ministério da Educação, Pordata e Banco de Portugal (2019). 


\section{Autuaŗão}

ISSN: 1984-6444 | http://dx.doi.org/10.5902/1984644432179

Como ilustrado no Quadro 4, os encargos totais anuais para o Estado com um professor situado no Índice 167 (início da carreira para um professor do quadro) situam-se na ordem dos 27 mil euros. Contudo, este encargo decresce logo em cerca de 6.335 euros ao assumirmos benefícios financeiros públicos diretos para o Estado, ao arrecadar os valores correspondentes à retenção na fonte de IRS, contribuições para a Segurança Social ou Caixa Geral de Aposentações e ADSE. Se, adicionalmente, forem assumidos outros benefícios financeiros indiretos, o vencimento líquido anual estaria na ordem dos 19.070,93 euros.

De acordo com a projeção indicada no Quadro 3, os 1.057 novos horários a criar representariam um custo bruto para o Estado na ordem dos 29 milhões de euros. Tendo em conta os valores deste mesmo Quadro $3 \mathrm{e}$, adicionalmente, ao se mobilizarem os valores estimados neste percurso metodológico, patentes no Quadro 4, foi possível obter os valores que se seguem, impactos financeiros perspetivados para o ano letivo de 2017/2018 e a preços de referência desse mesmo ano.

Quadro 5 - Custos Brutos e Custos Líquidos decorrentes dos horários docentes a criar em 2017/2018, a preços de 2017/2018

\begin{tabular}{|c|c|c|}
\hline ANOS DE INÍCIO DE CICLO & $\begin{array}{c}\text { CUSTOS BRUTOS } \\
\text { (ÍNDICE 167), EM } \\
\text { EUROS }\end{array}$ & $\begin{array}{c}\text { CUSTOS } \\
\text { LíQUIDOS (ÍNDICE } \\
\text { 167), EM EUROS }\end{array}$ \\
\hline $1^{\circ}$ ano & 5929451,22 & 4138391,81 \\
\hline $5^{\circ}$ ano & 4863789,48 & 3394625,54 \\
\hline $7^{\circ}$ ano & 6448619,76 & 4500739,48 \\
\hline $1^{\circ}$ ano - Cursos Científico-Humanísticos \\
(Ensino Regular)
\end{tabular}

Fonte: Elaboração própria.

Da análise do Quadro 5 ressalta a evidência de que se for assumido o valor base por docente, no Índice 167, em termos líquidos - os tais 19.070,93 euros - em detrimento dos $27.324,66$ euros adstritos a uma perspetiva de custos brutos, o custo 


\section{Autuaŗão}

ISSN: 1984-6444 | http://dx.doi.org/10.5902/1984644432179

real para o Estado não seriam os quase 29 milhões de euros, mas sim, cerca de 20 milhões, representando uma contração dos encargos na ordem dos $30 \%$.

Os valores apresentados clarificam, assim, que o custo efetivo para o Estado é significativamente inferior ao que seria à partida expectável. Independentemente do facto de, no caso português, a redução do número de alunos por turma possa eventualmente não vir a exigir mais contratações em virtude da questão demográfica e de uma ação administrativa efetiva de redistribuição dos alunos entre turmas sobredimensionadas e subdimensionadas (sendo estas cerca de dois terços do total), o que se pretendia mesmo mostrar é a falácia dos decisores públicos quando se limitam a considerar despesas brutas. Enquadrada nesta visão redutora, encontra-se igualmente a perspetiva, muitas vezes negligenciada por eles, das externalidades positivas futuras que decorrem de uma população mais qualificada, conforme amplamente descrito pela literatura.

Também conforme indicado na literatura, e comprovado na realidade portuguesa, uma política de redução do número de alunos por turma tem efeitos pedagógicos que se repercutem na diminuição do número de alunos retidos. Neste âmbito, pode-se dizer que a redução do número de alunos por turma vem contribuir para reforçar o objetivo do Ministério da Educação em diminuir, em $50 \%$, a taxa de retenção atual dos alunos do ensino básico (ensino médio) até 2020 (Programa Nacional de Promoção do Sucesso Escolar) e na expectativa que se tenha cumprido $25 \%$ de quebra da taxa de retenção até 2018. Esta diminuição da retenção tem, obviamente, efeitos monetários que a seguir se tentam medir.

Neste enquadramento, iniciam-se algumas análises complementares, tendo por base os dados do projeto de investigação, mas com dados oficiais recentes já disponíveis.

De registar que todos os valores utilizados dizem respeito ao ano letivo de 2017/2018 quando se trata de alunos matriculados e à execução orçamental, enquanto que os valores das taxas de retenção são relativas ao último ano com dados disponíveis, neste caso o de 2016/2017.

O Quadro 6 apresenta um custo médio por aluno tendo em conta a execução orçamental do Estado português e o total de alunos matriculados no ano letivo de 


\section{Althapẫ}

ISSN: 1984-6444 | http://dx.doi.org/10.5902/1984644432179

2017/2018. No Quadro 7 são indicados os valores relativos aos alunos por ciclo, respetivas taxas de retenção e alunos retidos.

Quadro 6 - Custo médio por aluno em função do total de alunos em 2017/2018 e da execução orçamental em 2018

\begin{tabular}{|l|c|}
\hline \multicolumn{1}{|c|}{ DESCRIÇÃO } & VALORES \\
\hline Total de Alunos do Ensino Básico e Secundário (2017/2018) (1) & 1399781 \\
\hline Execução Orçamental 2018 (2) & 4804000000 Euros \\
\hline Custo Médio por Aluno (3)=(2)/(1) & 3431,97 Euros \\
\hline
\end{tabular}

Fonte: Elaboração própria - Dados obtidos no Ministério da Educação e Banco de Portugal (2019).

Quadro 7 - Número total e taxas de retenção de alunos, por ciclos de ensino, em 2017/2018

\begin{tabular}{|c|c|c|c|}
\hline DESCRIÇÃO & $\begin{array}{c}\text { № DE ALUNOS } \\
\text { MATRICULADOS }\end{array}$ & $\begin{array}{c}\text { TAXAS DE RETENÇÃO } \\
\mathbf{( 1 6 / 1 7 )}\end{array}$ & $\begin{array}{c}\text { № DE ALUNOS } \\
\text { RETIDOS }\end{array}$ \\
\hline Alunos do $1^{\circ}$ ciclo & 404010 & $3 \%$ & 12120 \\
\hline Alunos do $2^{\circ}$ ciclo & 225794 & $5,8 \%$ & 13096 \\
\hline Alunos do $3^{\circ}$ ciclo & 370202 & $8,5 \%$ & 31467 \\
\hline
\end{tabular}

Fonte: Elaboração própria - Dados obtidos no Ministério da Educação e Pordata (2019).

A partir dos quadros acima e triangulando com a meta pretendida de redução em $25 \%$ e 50\% do número de retenções, até 2018 e 2020, respetivamente, segundo o "Programa Promoção do Sucesso Escolar", obteve-se um valor que se pode considerar poder desonerar o orçamento do Ministério da Educação em cerca de 48 milhões de euros assumindo uma quebra de $25 \%$ nas retenções, fixando-se em quase 100 milhões de euros se for alcançada uma quebra de $50 \%$ nas retenções, conforme se pode observar no Quadro 8.

Quadro 8 - Poupança assumindo uma redução de $25 \%$ e de $50 \%$ de retenções de alunos, em função do $\mathrm{n}^{\circ}$ total de alunos retidos e respetivo custo por aluno, em 2017/2018

\begin{tabular}{|c|c|}
\hline DESCRIÇÃO & VALORES \\
\hline Total Alunos Retidos & 56683 \\
\hline № de alunos - Meta "-25\% Retenções" & 14171 \\
\hline Custo Total com Alunos Retidos & 194534355,5 euros \\
\hline Poupança com Meta "-25\% Retenções" & 48633588,88 euros \\
\hline Poupança com Meta "-50\% Retenções" & 97267177,75 euros \\
\hline
\end{tabular}

Fonte: Elaboração própria. 


\section{工 Wusm eutuarao}

ISSN: 1984-6444 | http://dx.doi.org/10.5902/1984644432179

Tendo presente todo o percurso e cálculos anteriores, e em jeito de síntese, no Quadro 9 pretende-se evidenciar os custos adicionais de uma redução no número de alunos por turma no sistema educativo português, comparando com alguns valores que poderiam desonerar o orçamento público, assumindo os benefícios para o sistema educativo português de turmas de menor dimensão. Para isso, tomámos como referência o custo unitário da construção de uma nova sala de aula, na ordem de 150 mil euros e o seu respetivo equipamento na ordem de 4,5 mil euros (MINISTÉRIO DA EDUCAÇÃO, 2019). Além disso, assume-se do lado de possíveis poupanças, os encargos com programas relativos ao abandono e insucesso escolares e os montantes já estimados relativos a uma quebra nos valores da retenção escolar.

Quadro 9 - Estimativas relativas a encargos adicionais e poupanças resultantes de uma redução do número de alunos por turma em 2017/2018

\begin{tabular}{|c|c|c|c|}
\hline $\begin{array}{c}\text { ENCARGOS } \\
\text { ADICIONAIS }\end{array}$ & EUROS & POUPANÇAS & EUROS \\
\hline Professores & 20157973,01 & $\begin{array}{c}\text { Programa "Insucesso } \\
\text { e Abandono Escolar" } \\
- \text { TEIP 3 }\end{array}$ & 20418987,67 \\
\hline $\begin{array}{c}\text { Construção de novas } \\
\text { salas de aula }\end{array}$ & $\begin{array}{c}3300000 \\
\text { (22 salas * } 150000 \\
\text { euros })\end{array}$ & $\begin{array}{c}\text { Meta "-25\% } \\
\text { Retenção" }\end{array}$ & 48633588,88 \\
\hline $\begin{array}{c}\text { Equipamento de novas } \\
\text { salas de aula }\end{array}$ & $\begin{array}{c}99000 \\
\text { (22 salas * 4500 euros) }\end{array}$ & & $\mathbf{6 9} \mathbf{0 5 2 5 7 6 , 5 5}$ \\
\hline Totais & $\mathbf{2 3 5 5 6 9 7 3 , 0 1}$ & & \\
\hline
\end{tabular}

Fonte: Elaboração própria - Dados obtidos no Ministério da Educação (2019).

Os valores apresentados evidenciam que o custo real para o Estado português é significativamente menor daquele que se poderia esperar a priori, na medida em que, a eliminação das despesas com programas de combate ao abandono e insucesso escolares e as referentes à retenção dos alunos, permitiria uma poupança na ordem dos 69 milhões de euros. 


\section{Usm

ISSN: 1984-6444 | http://dx.doi.org/10.5902/1984644432179

\section{Considerações Finais}

Pretendeu-se, com este trabalho, para além da mobilização de literatura respeitante a uma política educativa de redução do número de alunos por turma, com enfoque nos seus impactos financeiros, apresentar um percurso metodológico que permitisse assumir alguns valores de referência para diferentes escalões da carreira docente e estimar custos mais realistas dessa política, tendo presente a realidade do sistema educativo português em 2017/2018.

No presente artigo procurou-se demonstrar, através das estimativas realizadas, que existem benefícios decorrentes da diminuição do número de alunos por turma e que os custos associados são, habitualmente, sobrevalorizados ao serem determinados em função dos custos brutos de um trabalhador para o Estado e não tendo presente os custos líquidos correspondentes, como consideramos ter ficado patente através dos cálculos apresentados.

Tendo em conta as projeções de turmas a criar, no sistema educativo português, no ano letivo de 2017/2018, estimou-se que os custos líquidos desta medida se situariam na ordem dos 20 milhões de euros, um valor significativamente inferior aos que são, recorrentemente, assumidos pelos decisores políticos. Já no que concerne às estimativas relacionadas com as metas de redução em $25 \%$ e $50 \%$ das retenções, os resultados apontam para uma poupança na ordem dos 48 milhões de euros e 100 milhões de euros, respetivamente.

Este trabalho pretende, assim, contribuir para uma maior e mais afinada reflexão sobre estas temáticas, não apenas no contexto do sistema educativo português, mas igualmente, em contextos educativos de outros países, sensibilizando-se os diferentes atores - educativos e políticos - para os benefícios e custos diretos e indiretos de uma política de redução do número de alunos por turma.

\section{Referências}

BANCO DE PORTUGAL. Estatísticas do Banco de Portugal - Indicadores Económicos. Disponível em: https://www.bportugal.pt/indicadores?mlid=1042. Acesso em: 1 mar. 2019.

BARDIN, Laurence. Análise de conteúdo. Lisboa: Edições 70, 2009. 


\section{Us:

ISSN: 1984-6444 | http://dx.doi.org/10.5902/1984644432179

BECKER, Gary. Human Capital: A Theoretical and Empirical Analysis, with Special Reference to Education. Chicago: University of Chicago Press, 1964.

BLATCHFORD, Peter; CHAN, Kam; GALTON, Maurice; LAI, Kwok; LEE, Chi. Class Size Eastern and Western Perspectives. New York: Routledge, 2016.

BOGDAN, Robert; BIKLEN, Sari. Investigação qualitativa em educação - uma introdução à teoria e aos métodos. Porto: Porto Editora, 1994.

CABRITO, Belmiro Gil. Financiamento do Ensino Superior. Lisboa: EDUCA, 2002.

CAPUCHA, Luís; CABRITO, Belmiro Gil; CARVALHO, Helena; SEBASTIÃO, João; MARTINS, Susana da Cruz; CAPUCHA, Ana Rita; ROLDÃO, Cristina; TAVARES, Inês; MUCHARREIRA, Pedro Ribeiro. A Dimensão das Turmas no Sistema Educativo Português. Lisboa: Ministério da Educação, 2017. Disponível em: https://www.portugal.gov.pt/pt/gc21/comunicacao/documento?i=a-dimensao-dasturmas-no-sistema-educativo-portugues. Acesso em: 29 dez. 2018.

FINN, Jeremy; ACHILLES, Charles. Tennessee's Class Size Study: Findings, Implications, Misconceptions. Educational Evaluation and Policy Analysis, v. 21, n. 2, p. 97-109, 1999.

HANUSHEK, Eric. Assessing the Effects of School Resources on Student Performance: An Update. Educational Evaluation and Policy Analysis Summer, v. 19 , n. 2, p. 141-164, 1997.

HARFITT, Gary James. Class Size Reduction. Key Insights from Secondary School Classrooms. Singapore: Springer, 2015.

JEPSEN, Christopher; RIVKIN, Steven. Class size reduction and student achievement: The potential tradeoff between teacher quality and class size. Journal of Human Resources, v. 44, n. 1, p. 223 - 250, 2009.

KRUEGER, Alan. Economic considerations and class size. Economic Journal, n. 113 , p. $34-63,2003$.

KRUEGER, Alan. Experimental estimates of education production functions. The Quarterly Journal of Economics, v. 114, n. 2, p. 497-532, 1999.

MINISTÉRIO DA EDUCAÇÃO. Estatísticas da DGEEC. Disponível em: http://www.dgeec.mec.pt/np4/home. Acesso em: 16 fev. 2019.

MITCHELL, Douglas; MITCHELL, Ross. The Political Economy of Education Policy: The Case of Class Size Reduction. Peabody Journal of Education, v. 78, n. 4, p. 120-152, 2003. 


\section{usm

ISSN: 1984-6444 | http://dx.doi.org/10.5902/1984644432179

MUCHARREIRA, Pedro Ribeiro. Formação contínua centrada na escola e currículo do mar - o caso de uma escola inaciana. Educar em Revista, v. 34, n. 72, p. 285302, 2018.

MUCHARREIRA, Pedro Ribeiro. O papel da formação contínua, centrada na escola, na (re)construção do projeto educativo e no desenvolvimento profissional docente - um estudo de caso. Lisboa: Instituto de Educação da Universidade de Lisboa, 2017.

MUCHARREIRA, Pedro Ribeiro. Formação contínua centrada na escola e desenvolvimento profissional docente: um estudo de caso. Educação em Questão, v. 54, n. 42, p. 38-64, 2016.

MUCHARREIRA, Pedro Ribeiro; ANTUNES, Marina Godinho. Os efeitos das variáveis macroeconómicas no desempenho das organizações: Evidência das pequenas e médias empresas em Portugal. Contabilidade \& Gestão - Portuguese Journal of Accounting and Management - Revista Científica da Ordem dos Contabilistas Certificados, n. 17, p. 113-143, 2015.

MUCHARREIRA, Pedro Ribeiro; CABRITO, Belmiro; CERDEIRA, Luísa. A formação docente em Portugal: o papel das instituições do ensino superior na formação dos educadores de infância e dos professores do ensino básico e secundário. In CABRITO, Belmiro; MACEDO, Jussara; CERDEIRA, Luísa (Orgs.). Ensino Superior no Brasil e em Portugal - atualidades, questões e inquietações. Lisboa: Educa, 207-226, 2018.

NORMORE, Anthony; ILON, Lynn. Cost-Effective School Inputs Is Class Size Reduction the Best Educational Expenditure for Florida?. Educational Policy, v. 20, n. 2, p. 429-454, 2006.

PORDATA. Estatísticas de Portugal. Disponível em: https://www.pordata.pt/Portugal. Acesso em: 28 fev. 2019.

PORTUGAL. Diário da República - Despacho Normativo n. 10-A/2018. Disponível em: https://dre.pt/application/file/a/115552693. Acesso em: 1 jul. 2018.

PSACHAROPOULOS, George. Returns to Investment in Education: A Global Update. World Development, v. 22, n. 9, p. 1325-1343, 1994.

PSACHAROPOULOS, George; PATRINOS, Harry Anthony. Returns to Investment in Education: A Further Update. Education Economics, v. 12, n. 2, p. 111-134, 2004.

SCHULTZ, Theodore. Investment in Human Capital. American Economic Review, v. 51, n. 1, p. 1-17, 1961.

SERVE. Financing class size reduction. Greensboro, NC: University of North Carolina School of Education, 2005. 


\section{Ailloapẫ}

ISSN: 1984-6444 | http://dx.doi.org/10.5902/1984644432179

WHITEHURST, Grover; CHINGOS, Matthew. Class Size: What Research Says and What it Means for State Policy. Washington D.C.: Brown Center on Education Policy, 2011.

\section{Correspondência}

Pedro Ribeiro Mucharreira - Professor Doutor na Universidade de Lisboa, Lisboa, Portugal.

ORCID: http://orcid.org/0000-0003-0059-0576

Belmiro Gil Cabrito - Professor Doutor na Universidade de Lisboa, Lisboa, Portugal. ORCID: http://orcid.org/0000-0003-0420-5639

Luís Capucha - Professor Doutor no Instituto Universitário de Lisboa (ISCTE-IUL), Lisboa, Portugal.

ORCID: http://orcid.org/0000-0002-4173-9309

Instituto de Educação, Universidade de Lisboa. Alameda da Universidade - Cidade Universitária, Lisboa: 1649-013 Lisboa, Lisboa, Portugal.

E-mail: prmucharreira@ie.ulisboa.pt - b.cabrito@ie.ulisboa.pt - luis.capucha@iscte-iul.pt

Recebido em 13 de abril de 2018

Aprovado em 22 de fevereiro de 2019

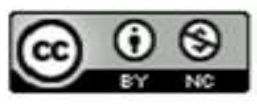

This work is licensed under a Creative Commons Attribution-NonCommercial 4.0 International (CC BY-NC 4.0) 